\title{
Comment on: "Evaluation of Facebook and Twitter Monitoring to Detect Safety Signals for Medical Products: An Analysis of Recent FDA Safety Alerts"
}

\author{
Viroj Wiwanitkit ${ }^{1}$
}

Published online: 19 April 2017

(C) Springer International Publishing Switzerland 2017

Dear Editor,

In a recent article in Drug Safety entitled "Evaluation of Facebook and Twitter Monitoring to Detect Safety Signals for Medical Products: An Analysis of Recent FDA Safety Alerts," Pierce et al. concluded that "an efficient semiautomated approach to social media monitoring may provide earlier insights into certain adverse events" [1]. The question, however, that remains is how the efficiency of such an approach should be measured. In fact, both Facebook and Twitter are widely used computational online tools that need a code of conduct in usage. Adverse drug reaction-related posts are common in these platforms [2]. The basic issue with these social media platforms is of confidentiality and privacy. It remains to be seen how validity and reliability of the posted data are tested, and this issue requires further research and discussion.

\section{Compliance with Ethical Standards}

Funding No sources of funding were used to assist with the preparation of this letter.

Conflict of interest Viroj Wiwanitkit has no conflicts of interest directly relevant to the content of this letter.

\section{References}

1. Pierce CE, Bouri K, Pamer C, Proestel S, Rodriguez HW, Van Le H, Freifeld CC, Brownstein JS, Walderhaug M, Edwards IR, Dasgupta N. Evaluation of Facebook and Twitter monitoring to detect safety signals for medical products: an analysis of recent FDA safety alerts. Drug Saf. 2017;40(4):317-31.

2. Freifeld CC, Brownstein JS, Menone CM, Bao W, Filice R, KassHout T, Dasgupta N. Digital drug safety surveillance: monitoring pharmaceutical products in twitter. Drug Saf. 2014;37(5):343-50.

Viroj Wiwanitkit

wviroj@yahoo.com

1 Hainan Medical University, Haikou, China 